\title{
Impacts of Temporal Changes in Land use/cover on the Remaining Historical Forests in a Rapidly Urbanizing area
}

Jingyi Yang ( $\nabla$ jyyang1@gzu.edu.cn )

Guizhou University https://orcid.org/0000-0002-8588-5658

\section{Feng Wu}

Guizhou University

\section{Research}

Keywords: Historical forests, Land use/cover change, Loss, Threat, Critical areas, Connectivity

Posted Date: May 4th, 2021

DOl: https://doi.org/10.21203/rs.3.rs-466357/v1

License: (c) (i) This work is licensed under a Creative Commons Attribution 4.0 International License.

Read Full License 
Impacts of temporal changes in land use/cover on the remaining historical forests

in a rapidly urbanizing area

Jingyi Yang ${ }^{\mathrm{a},{ }^{*}}$, Feng $\mathrm{Wu}^{\mathrm{b}}$

${ }^{a}$ College of Forestry, Guizhou University, Guiyang, 550025, China

${ }^{\mathrm{b}}$ Institute for Forest Resources \& Environment of Guizhou, Guizhou University, Guiyang 550025, China

Jingyi Yang, jyyang1@gzu.edu.cn; FengWu, fwu@gzu.edu.cn;

Corresponding author:

Jingyi Yang

E-mail: jyyang1@gzu.edu.cn

College of Forestry, Guizhou University, Guiyang, 550025, China

Tel: (86) 18285079315 


\begin{abstract}
Background: Remaining historical forests are crucial for maintaining biodiversity in urban areas. However, the integrity and stability of historical forests are affected by land use/cover change in various ways. A better understanding of these impacts can help guide targeted conservation.
\end{abstract}

Methods: In this study, we estimated the loss of forestlands and levels of threats and analysed the importance of critical areas for historical forests in the built-up area of a rapidly urbanizing city-Guiyang, China.

Results and Conclusions: The results showed that 1988.46 ha of historical forestlands was transformed into other land use/cover types. The number of patches smaller than 10 ha increased by $51 \%$ from 1976 to 2018 . The lands of 36 historical forest patches were completely transformed into other land use/cover types during the past 42 years. The mean value of the threat index of all the historical forest patches increased by $33 \%$ compared to the baseline year. Core and bridge areas regarded as key nodes and links for the connectivity of forest networks decreased in area by 632.34 and 331.92 ha, respectively. Most of the critical areas with high importance values for connectivity were located in the central part of the city. They were severely threatened by the surrounding areas, having high threat index values. Based on these findings, we recommend that effective measures be implemented to control the further loss of historical forests and increase the connectivity and buffering capacity of the remaining forests by planting trees in some key locations.

Key words: Historical forests, Land use/cover change, Loss, Threat, Critical areas, 


\section{Connectivity}

\section{Background}

Rapid urbanization causes an extensive transformation of land use in a city, which leads to a massive loss and fragmentation of original intact forests (Ramalho et al. 2014; Stiles and Scheiner 2010; Zipperer 2002). Although the historical forests currently retained in urban areas are fragmented and degraded, they are still able to provide more efficient ecosystem services to urban residents and can support high biodiversity (Derkzen et al. 2015; Kowarik and von der Lippe 2018; Niemelä et al. 2010). They have a more complex stand structure and more resilient and stable biological communities than newly planted forests (Fahey and Casali 2017). Despite these benefits and importance, the dispersal, reproduction and survival of plants in the remaining historical forests are impeded by the surrounding unsuitable environments due to the poor connectivity of urban forest ecosystems (Lopez et al. 2018; Smale and Gardner 1999; Williams and Winfree 2013).

The remaining historical forests in a city are severely affected by urban expansion. Several studies have reported that the area of historical forests greatly decreases due to land-use change during urbanization. For example, the historical forest area remaining within the greater Chicago region in 2010 was reduced by $40 \%$ relative to that in 1939, and the core areas in 2010 were only one-third of those in 1939 (Fahey and Casali 2017). There was a 15\% decrease in the remnant forest cover from 1990 to 2015 in Eastern Ghats, India (Salghuna et al. 2018). Human activity (e.g., trampling, cutting and tree injuring) reduced plant diversity and canopy density 
and even led to the local extinction of some plant species in historical forests (Bagnall 1979). Ranta et al. (2013) indicated that the edge effect of urban forest remnants facilitated new species, while some original forest species gradually disappeared based on a survey conducted in 1980 and 2000 in Tampere, Finland. Yang et al. (2014) found an increase in small stems in remnant forest from the outskirts to the inner city in Chongqing, China.

Current studies on the impacts of urbanization on historical forests have mainly focused on landscape metrics of the remnant patch itself or the surrounding matrix, which can be evaluated by patch-based computation software at the patch, class and landscape levels (e.g., Fragstats software). Many studies have found that the size of remnant patches has significant impacts on the plant diversity of historical forests (Ramalho et al. 2014; Stiles and Scheiner 2010; Yang et al. 2020). Patch size can influence the amount of room that remnants can provide for the survival of individuals and the buffering capacity of remnants when affected by surrounding environments (Hansen and DeFries 2007; Maiorano et al. 2008; Scheiner and Willig 2005). The shape of the patch is also an important predictor of the biodiversity of the remaining patches because complex geometric shapes may facilitate the communication of organisms between the patch and the surrounding matrix (Stamps et al. 1987; Yamaura et al. 2008). Moreover, the percentage of surrounding impervious surfaces was negatively correlated with the plant diversity of the remnant due to their resistance to the flow of organisms between remnants (Caryl et al. 2013; Malkinson et al. 2018; Niu et al. 2018). In addition, compositional and configurational 
metrics of the surrounding matrix calculated by Fragstats software were associated with the productivity of urban natural remnants, and the productivity was mediated by buffer size and time (Fernández et al. 2018).

While existing studies have provided useful knowledge about the effect of urbanization on historical forests, some issues are worth addressing to improve our understanding. First, existing studies have mainly concentrated on the impact of landscape patterns based on the current situation of urban land use (Huang et al. 2013; Williams and Winfree 2013; Yang et al. 2020). Few studies have considered the association between temporal changes in urban land use and the formation process of historical forest patches in a city (Han et al. 2019). Understanding the historical information of remaining forests during the process of urbanization in a city is beneficial for the development of more effective conservation activities based on historical trends and laws (Ramalho and Hobbs 2012). Second, most studies have quantified the direct effect of urban land-use change (area loss, habitat fragmentation) but have not estimated the potential risks of historical forests threatened by these changes (Ramalho et al. 2018; Salghuna et al. 2018). The remaining forests surrounded by urban matrices also have different levels of degradation risk, even without the further loss of area (Hosonuma et al. 2012). Furthermore, most previous studies used landscape metrics, which measure only the structural connectivity of habitats but seldom consider both structural and functional connectivity (Lees and Peres 2008; Reider et al. 2018). The degrees of importance for individual forest patches to the overall connectivity of the historical forest ecosystem in a city were 
also uncertain in these studies. This lack of information is unfavourable for developing targeted conservation measures.

In this study, we intend to explore the impact of temporal changes in land use during urbanization on historical forests. We used the built-up area of a rapidly urbanizing mountainous city in the subtropical climate zone-Guiyang, China-as our study site. The specific objectives of this study were as follows: (1) to evaluate how the variation in loss and threat levels of historical forests are mediated by temporal changes in urban land use/cover; (2) to determine the importance of critical areas of historical forests combined with the measurement of both structural and functional connectivity; and (3) to discuss the implications of the findings for managing historical forests in Guiyang, China.

\section{Methods}

Study area

The city of Guiyang is famous in China for its karst landform and mountainous landscape. As the capital city of Guizhou Province, it is located in the central part of Guizhou and is bounded between $106^{\circ} 30^{\prime}$ to $106^{\circ} 59^{\prime} \mathrm{E}$ and $26^{\circ} 10^{\prime}$ to $26^{\circ} 49^{\prime} \mathrm{N}$. The forested mountain landscapes of Guiyang have been damaged by rapid urban expansion since 1996. However, due to the steep topography, many remaining and fragmented historical forest patches are scattered throughout the metropolitan area. This study was conducted in the built-up area of Guiyang, covering approximately $360 \mathrm{~km}^{2}$, including six districts.

\section{Identification of historical forest patches}


We used the land use/cover maps for 1976, 1993, 2001, 2009 and 2018, which were obtained from the Data Center for Resource and Environmental Science, Chinese Academy of Sciences (http://www.resdc.cn). The land cover data contain forestlands, grasslands, water bodies, urban lands, bare lands and farmlands (Xu et al. 2014). The gridded land cover data have a resolution of $30 \mathrm{~m}$ and an Albers Conic Equal Area projection. We identified the original forestlands in 1976 and the amount remaining in 1993, 2001, 2009 and 2018 that were not transformed into other land use/cover types; these regions were defined as historical forests. The forestlands in 2018 that did not originate from 1976 were regarded as newly planted forests.

\section{Transformation of original forestlands}

To evaluate the loss of original forestlands, we extracted the original forestlands that existed in 1976 and did not remain in 2018 using ArcGIS (version 10.2.2). Then, we estimated the area of these forestlands transformed into other land use/cover types during four periods: 1976-1993, 1993-2001, 2001-2009 and 2009-2018. We also calculated the number and area of the original forest patches that had completely transformed during the four periods.

\section{Assessment of threat levels}

We estimated the levels of threat posed by surroundings to historical forestlands using the Habitat Quality Model of InVEST (version 3.3.3). The threat indicator (TI) was calculated using the approach developed by Sharp et al. (2016), which is expressed as Eq. (1):

$$
T I_{x}=\sum_{r=1}^{R} \sum_{y=1}^{Y_{r}}\left(\frac{W_{r}}{\sum_{r=1}^{R} W_{r}}\right) r_{y} I_{x y r} S_{r}
$$


where $r$ is the threat source. Here, we regarded urban land, farmland and bare land as the threat sources to historical forests. $R$ is the total number of all threat sources. $y$ is a grid in the raster map of threat source $r . Y_{r}$ is the total number of grids in the raster map of threat source $r . W_{r}$ is the weight of the threat level of threat source $\mathrm{r}$ to the historical forest. $r_{y}$ is used to identify whether grid $y$ is from threat source $r . S_{r}$ is the relative sensitivity of historical forests to threat source $r . x$ is a grid of historical forest. $I_{x y r}$ is the impact of grid $y$ from threat source $r$ on a grid of historical forest $x$, which is expressed as Eq. (2):

$$
I_{x y r}=1-\left(\frac{D_{x y}}{D_{r} \max }\right)
$$

where $D_{x y}$ is the distance between threat grid y and historical forest grid x. $D_{r} \max$ is the maximum effective distance of threat source r's reach across space. The values used in Eq. (1) and Eq. (2) refer to Terrado et al. (2016) and are reported in Table 1.

Table 1 Parameters of different threat sources

\begin{tabular}{cccc}
\hline Threat source & $W_{r}$ & $D_{r} \max$ & $S_{r}$ \\
\hline Urban land & 1.00 & 7.10 & 0.85 \\
Farmland & 0.68 & 4.00 & 0.70 \\
Bare land & 0.80 & 5.60 & 0.72 \\
\hline
\end{tabular}

\section{Morphological spatial pattern analysis}

Based on the land use/cover data for 2018, we identified different spatial elements of historical forests using morphological spatial pattern analysis (MSPA) (Soille and Vogt 2009). The MSPA was implemented by GuidosToolbox available at http://forest.jrc.ec.europa.eu/. The spatial patterns of historical forests were divided into seven classes at the pixel level by MSPA: core, bridge, edge, branch, islet, loop 
and perforation (Vogt et al. 2009). The edge width was set to a value of $60 \mathrm{~m} \mathrm{(2}$ pixels) because it is the suitable edge width for small animals and plants (Ives et al. 2011).

\section{Measurement of probability of connectivity}

To measure the connectivity of historical forests and identify the important core areas and bridges in the landscape, the probability of connectivity (PC) index and the importance values of the patches (dPC) were calculated with Conefor software (Saura and Torné 2009). The PC index can reflect habitat loss and landscape fragmentation well and is widely used in connectivity analysis (An et al. 2020; Laita et al. 2011; Velázquez et al. 2017). In this study, the dPC values of only cores, bridges, and islets with areas larger than 3 ha were evaluated for the connectivity of historical forests in the built-up area. Cores and bridges are important for maintaining connectivity as nodes and links, respectively, in landscape graph theory (Saura et al. 2011). The analysis included some relatively large islets because of their role as steppingstones in improving connectivity (Gao et al. 2019). The PC and dPC values were calculated using the following equations:

$$
\begin{aligned}
P C & =\sum_{i=1}^{n} \sum_{j=1}^{n} a_{i} a_{j} p_{i j}^{*} \\
d P C & =\frac{P C-P C_{\text {remove }}}{P C} \times 100
\end{aligned}
$$

where $a_{i}$ and $a_{j}$ are the areas of patch $i$ and patch $j$, respectively. $p_{i j}^{*}$ is the maximum product probability of all paths between patches $i$ and $j$. The threshold of distance for the connection between patches was set to $500 \mathrm{~m}$, which ensured the migration of urban animals (Gao et al. 2019). If the distance between patch $i$ and $j$ is 
smaller than the distance threshold, $p_{i j}^{*}$ is simply equal to the distance between patches $i$ and $j$. If patch $i$ and $j$ are more distant, the maximum probability path comprises several steps through intermediate steppingstone nodes (Saura and Torné 2009). $P C_{\text {remove }}$ is the $\mathrm{PC}$ value after removing the patch.

\section{Results}

\section{Transformation into other land use/cover}

In the built-up area of Guiyang, the area of historical forests decreased from 4890.69 ha in 1976 to 2902.23 ha in 2018 . The most severe loss of forests occurred in the eastern and southwestern regions of the built-up area (Fig. 1). The forest patches located in the middle region were preserved and are still relatively intact. The number of historical forest patches increased to 256 from 222 during the 1976-2018 period. In particular, the increase in small patches $(<10 \mathrm{ha}$ ) was approximately $51 \%$, while the decreases in middle patches (10-50 ha) and large patches ( $>50 \mathrm{ha})$ were $21 \%$ and 53\%, respectively, from 1976 to 2018 (Fig. 2). 

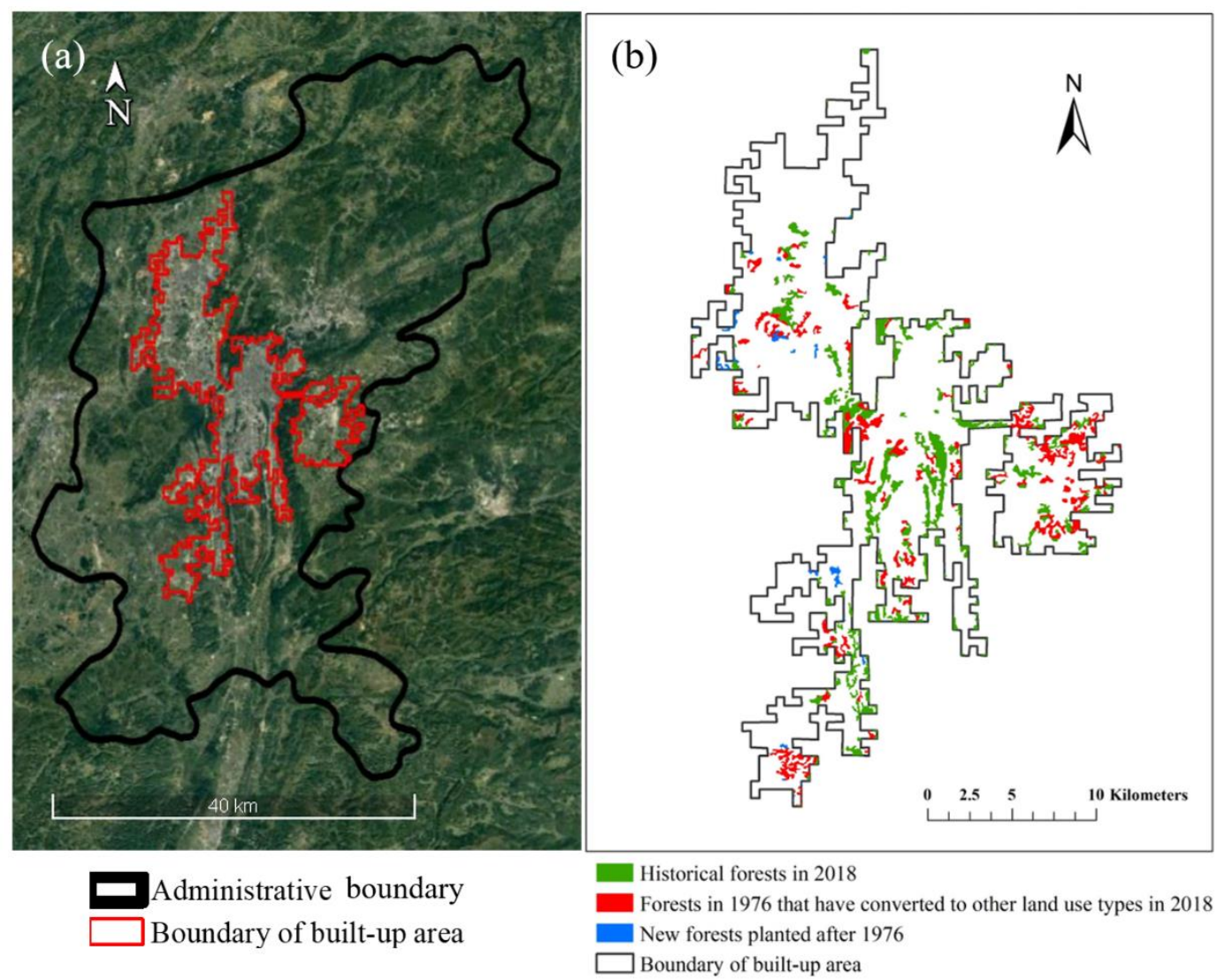

Fig. 1 The locations of historical forests. (a) The administrative boundary (black line) and boundary of built-up area (red line); (b) locations of historical forests that were retained, those that were transformed, and newly planted forests.

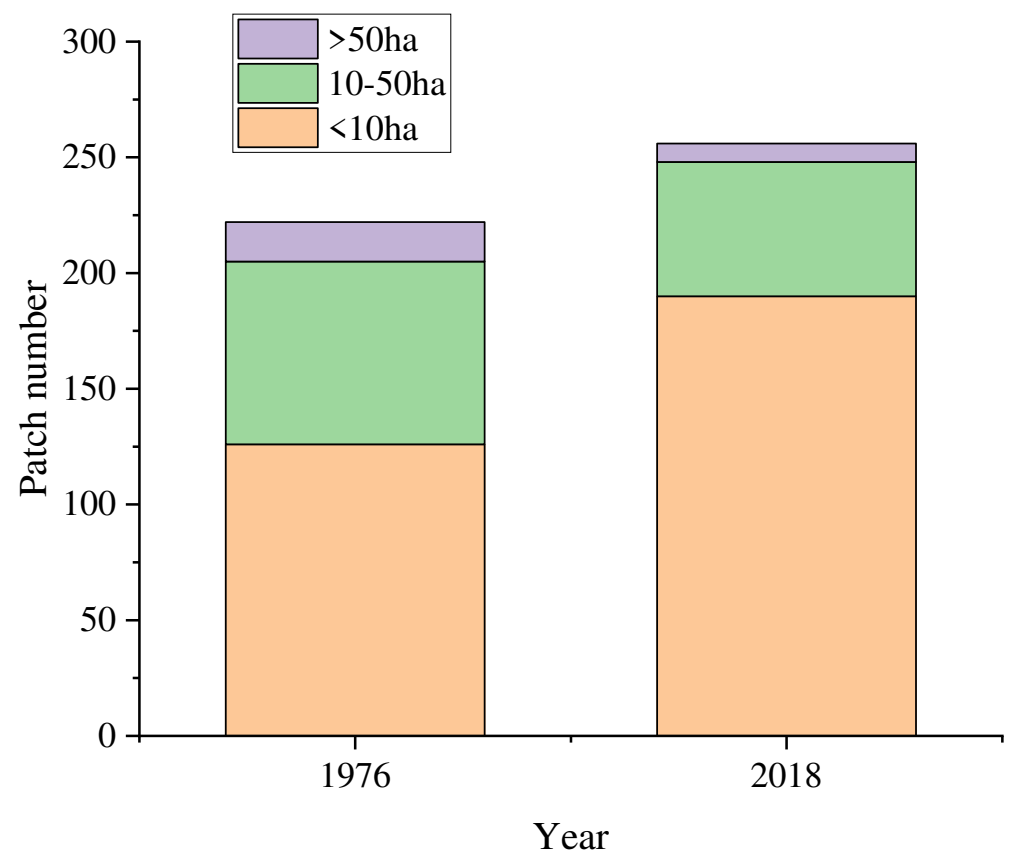

Fig. 2 The number of historical forest patches. 
By 2018, a total of 1988.46 ha of forestlands in 91 patches had been transformed into other land use/cover types, mainly into urban lands (Table 2). Notably, a large area of forest loss occurred during the period of 2009-2018. Among them, 35 of the original forest patches from 1976 were fully transformed into other land use/cover types by 2018 . However, only eight forest patches suffered a full loss by 2009, while 27 forest patches were completely transformed from 2009 to 2018 (Fig. 3).

Table 2 The temporal changes in transformed area (ha)

\begin{tabular}{llll}
\hline Period & Urban land & Cropland & Grassland \\
\hline $1976-1993$ & 124.65 & 8.73 & 0 \\
$1993-2001$ & 131.34 & 2.43 & 0 \\
$2001-2009$ & 237.24 & 0.45 & 1.08 \\
$2009-2018$ & 1490.13 & 3.51 & 1.17 \\
\hline
\end{tabular}

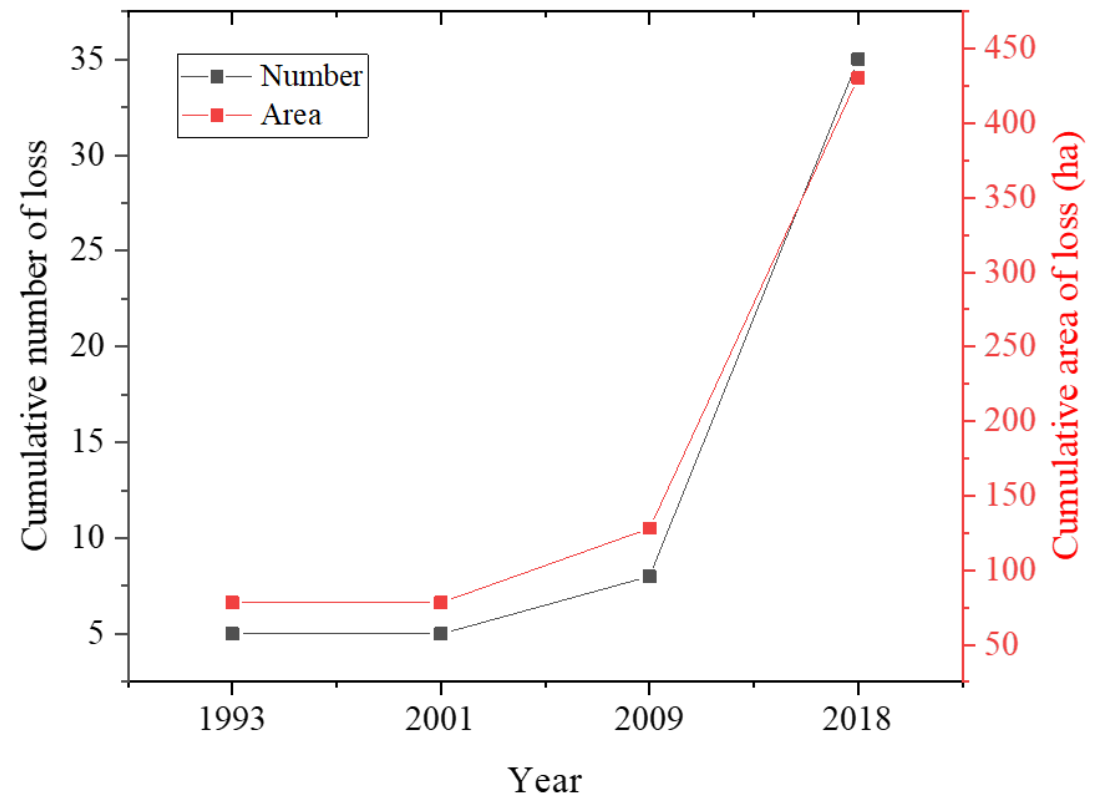

Fig. 3 The cumulative numbers and areas of loss for forest patches that were fully transformed into other land use/cover types.

Threats to historical forests 
Most historical forest patches in 2018 were threatened by surrounding environments much more than the forest patches were in 1976, as shown by the location of threat levels in Fig. 4. Compared to 1976, the mean TI value of historical forest patches increased by $33 \%$ in 2018 . In 1979,67 forest patches $(30 \%)$ had a TI value smaller than 0.1 ; however, this number decreased to only three historical forest patches (1\%) in 2018. In 2018, 18 historical forest patches (7\%) were seriously threatened (TI value $>0.2$ ). The TI values of forest patches showed a declining trend from the downtown to urban fringe regions.
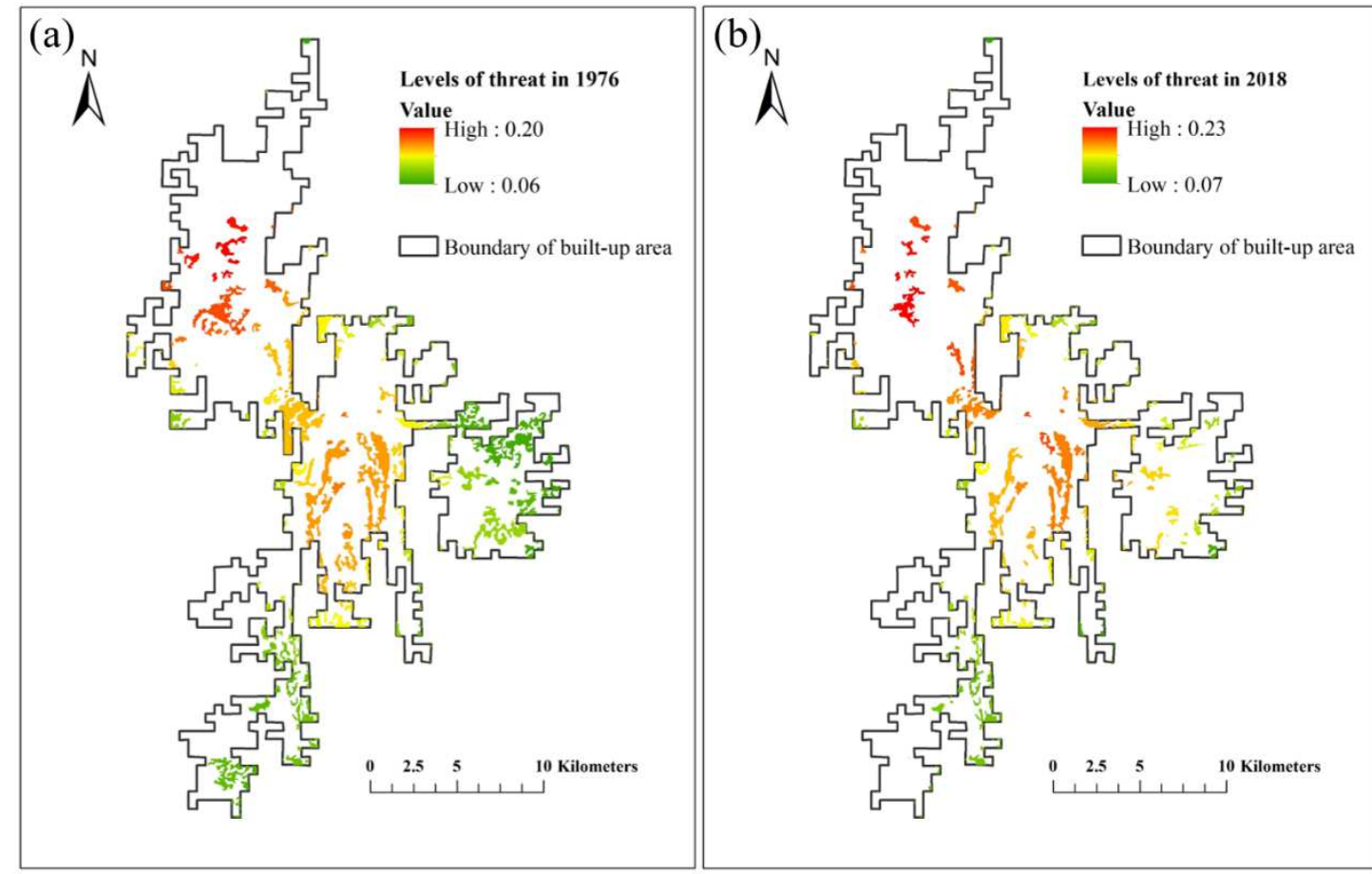

Fig. 4 Levels of threat to historical forest patches in (a) 1976 and (b) 2018.

\section{Morphological spatial patterns}

In the study area, the forest patches in 1976 were classified as follows: 332 cores, 153 bridges, 407 edges, 780 branches, 84 islets and 12 loops (Fig. 5a). In 2018, the historical forests were composed of 198 cores, 70 bridges, 208 edges, 488 branches 
and 133 islets (Fig. 5b). There were no perforations in the study area. Among the six morphological spatial pattern classes, the area of edges accounted for the majority of the total forest area (Fig. 6). The proportion of edges was nearly 40\% in 1976 and 2018. The cores and bridges, which are two indispensable elements, reduced considerably from 1976 to 2018 . Compared to 1976 , the area of cores decreased by $45 \%$, while that of bridges decreased by $61 \%$. Only the area of islets increased slightly during this period.
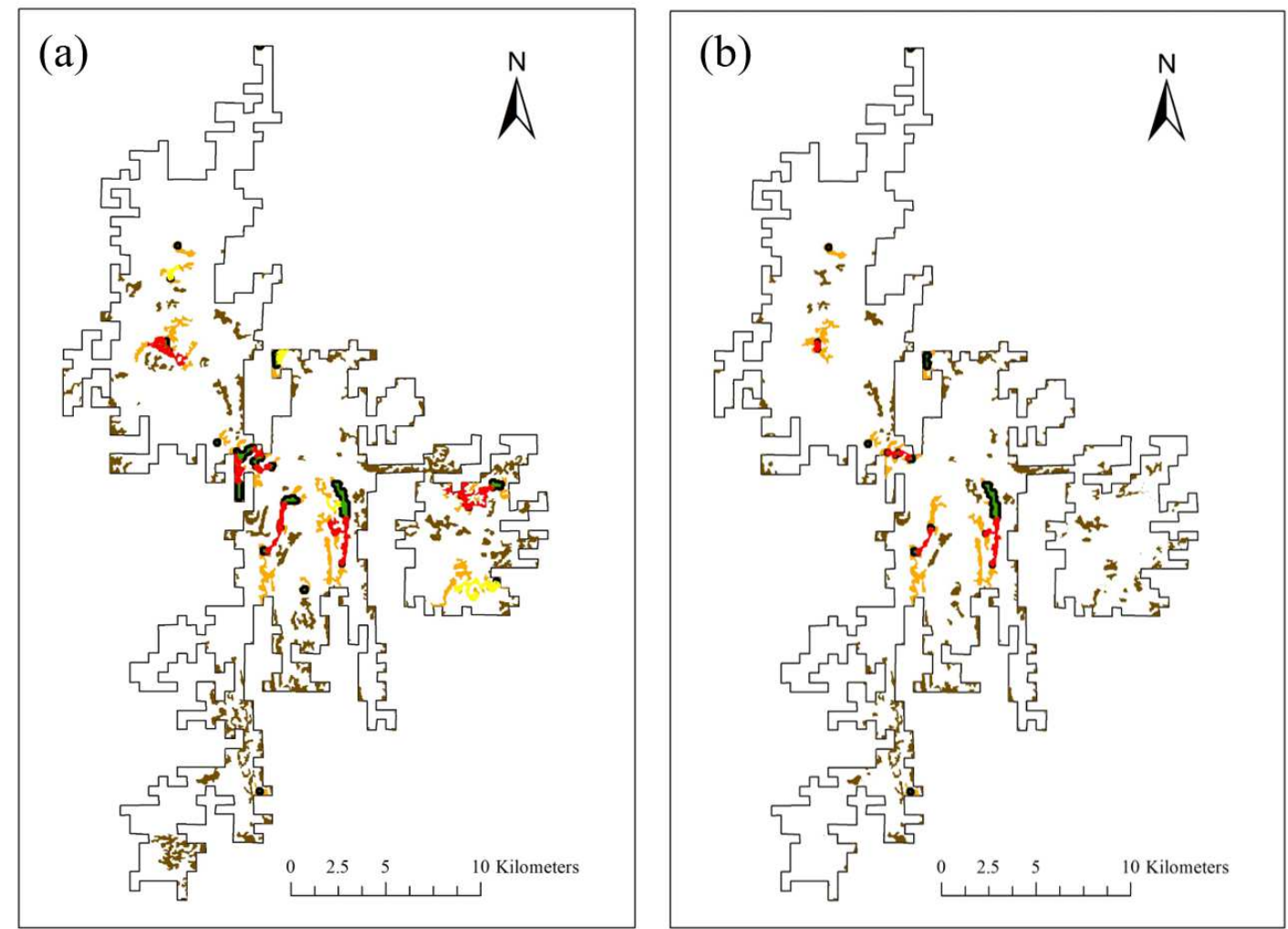

Branch Edge Islet Core Bridge $\square$ Loop $\square$ Boundary of built-up area

Fig. 5 Morphological spatial patterns of historical forests in (a) 1976 and (b) 2018. 


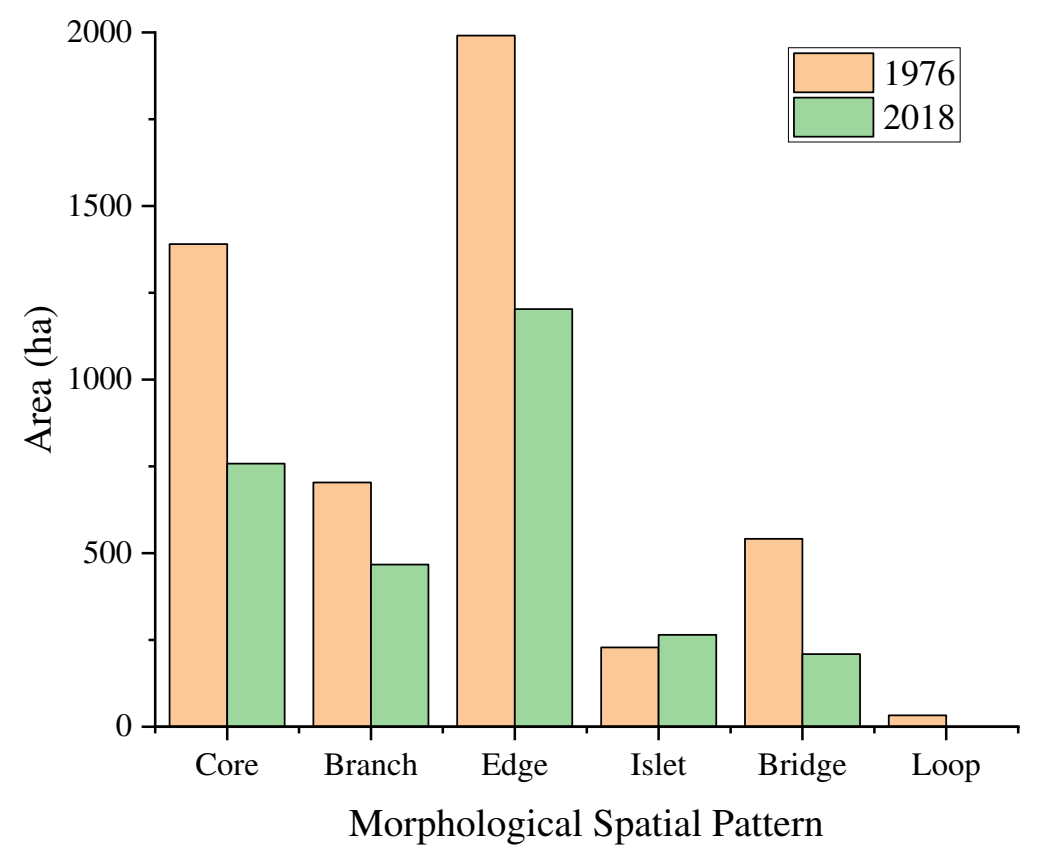

Fig. 6 The areas of different morphological spatial pattern classes of historical forests in 1976 and 2018.

\section{Probability of connectivity}

The PC values of cores, bridges and some islets are presented in Fig. 7. The top 10 most important cores were all located in the centre of the city, except for C7 and C10. All the top 10 important bridges were in the downtown area, which connected these important cores. Most of the cores and bridges next to the urban fringe had relatively low PC values. 


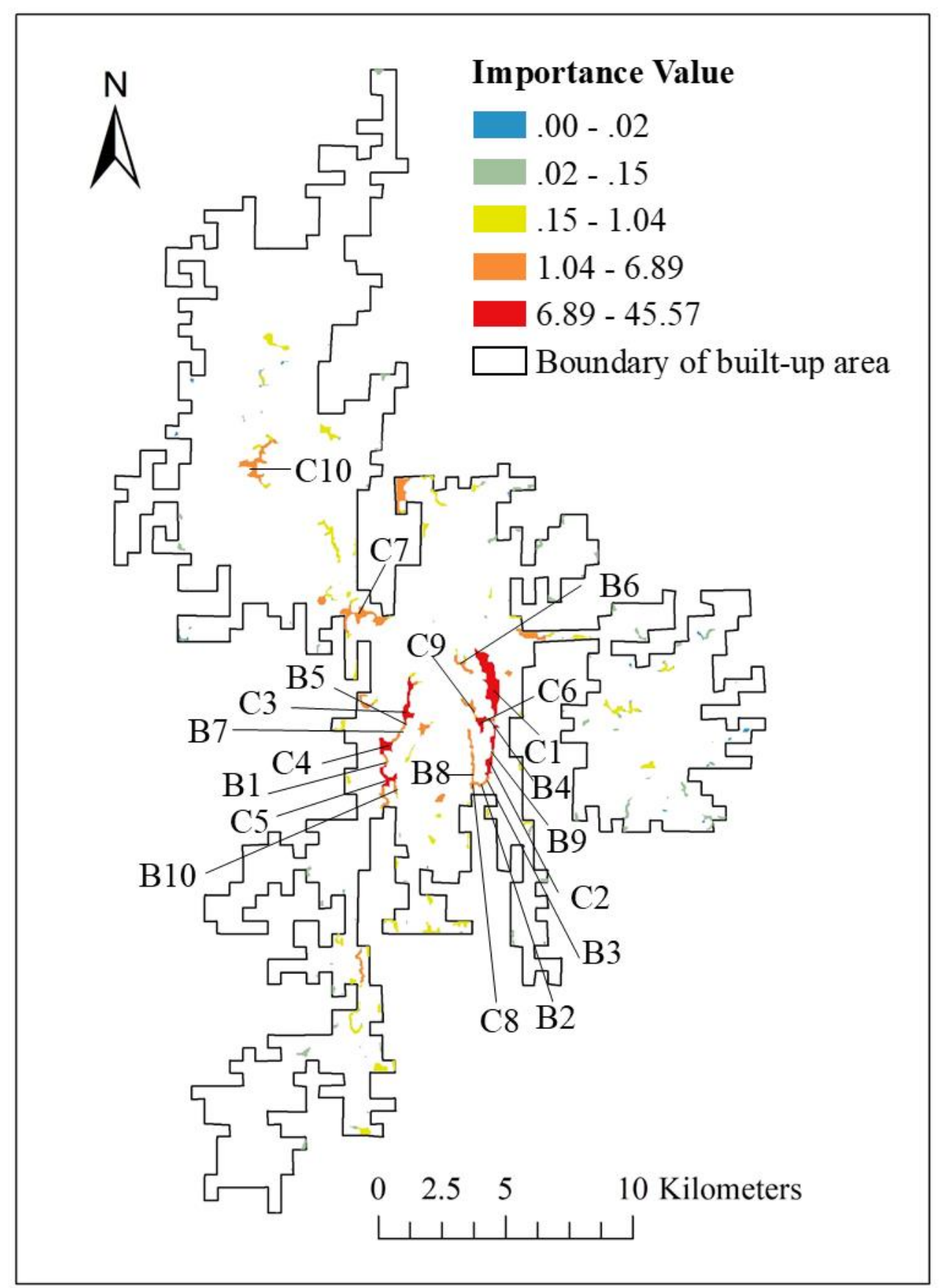

Fig. 7 Probability of connectivity values for historical forest patches.

Table 3 shows the area, PC values and threat levels of the top 10 important cores and bridges. The top important patch was also the largest patch in the built-up area, which was the most important due to its large area and central position. Relatively small cores (e.g., C2, C6, C8, and C9) were also important due to their role in 
connectivity of the whole landscape. The areas of most important bridges were relatively small, but they were vital for connecting important cores in the centre of the study area. It is remarkable, however, that these important cores and bridges were severely threatened by the surroundings. Their TI values were all above 0.15 (the average value of all the historical patches).

Table 3 Area, dPC values, threat levels, and spatial patterns of important cores and

\begin{tabular}{llll} 
& \multicolumn{3}{c}{ bridges } \\
\hline ID & Area (ha) & dPC value & TI \\
\hline C1 & 116.1 & 45.57 & 0.20 \\
C2 & 14.58 & 11.53 & 0.18 \\
C3 & 30.96 & 11.47 & 0.19 \\
C4 & 21.51 & 10.65 & 0.17 \\
C5 & 18.99 & 9.04 & 0.17 \\
C6 & 13.77 & 8.58 & 0.19 \\
C7 & 32.13 & 6.74 & 0.19 \\
C8 & 7.2 & 6.13 & 0.18 \\
C9 & 9.09 & 5.28 & 0.20 \\
C10 & 45.45 & 4.42 & 0.22 \\
B1 & 5.31 & 5.68 & 0.17 \\
B2 & 4.23 & 5.47 & 0.18 \\
B3 & 3.6 & 5.22 & 0.18 \\
B4 & 3.51 & 5.20 & 0.19 \\
B5 & 3.78 & 4.88 & 0.18 \\
B6 & 10.98 & 3.95 & 0.21 \\
B7 & 2.97 & 3.88 & 0.18 \\
B8 & 3.51 & 3.28 & 0.19 \\
B9 & 1.53 & 2.87 & 0.18 \\
B10 & 5.49 & 1.90 & 0.18 \\
\hline
\end{tabular}

\section{Discussion}

The impacts of urbanization on historical forests

The historical forestlands lost a significant amount of land area and were mainly 
converted into urban land-use types, especially during the $2009-2018$ period. The $41 \%$ decline in the total area of historical forests was driven by urbanization from 1976 to 2018. This finding was similar to that in other studies. For example, the total area of historical forests in the southern part of Seoul in 2015 decreased by $35 \%$ compared to the value in 1972 (Han et al. 2019). During the 2009-2018 period, we found that the area of historical forests in Guiyang declined dramatically. The primary reason for the observation was that the Chinese State Council released the "Several Opinions of the State Council on Further Promoting Sound and Fast Economic and Social Development in Guizhou" in 2012 (The Chinese State Council 2012). The economic situation and urbanization process of Guiyang city was relatively backward before this report due to its steep terrain and poor transportation, but the city entered a period of urbanization and very rapid development after 2012 (Yao et al. 2018).

The expansion of urban lands surrounding historical forest patches increased the threat levels to ecosystems. We found that the threat levels of historical forest patches increased from the urban fringe to the centre. Additionally, for several large and relatively intact patches in the centre of the city, although the area loss was less, the high urbanization intensity of the surroundings increased the risk of forest degradation. The consequences of intensive urbanization on urban forests are oxidative stress (Isaksson 2015), changes in biogeochemical cycles (Alberti 2010), biotic homogenization (Kuhn and Klotz 2006), etc. Observations from field studies also support this possibility that the taxonomic $\beta$-diversity of trees among forest patches in Guiyang city was low when the percentage of surrounding impervious area 
was high (Yang et al. 2020).

The historical forest patches in the study area were fragmented and judged by the spatial characteristics. The MSPA method can judge the spatial patterns simply and intuitively according to their functions (Vogt et al. 2009). For example, the spatial patterns of the study area were predominantly edges, and edges may be impacted by edge effects that are unfavourable for forest species sensitive to edge circumstances (Soga et al. 2013). The historical forest patches in the built-up area of Guiyang were mainly in the form of irregular elongated shapes, which may explain the high proportion of edges. Branches, which are interruptions of the bridge connection (An et al. 2020), also accounted for a relatively high proportion. Loops can facilitate species movements within the same patch (An et al. 2020), but they had the lowest proportion in the study area, even decreasing to zero in 2018. Cores can serve as ecological source areas, while bridges can enhance the connectivity among cores (Velázquez et al. 2017). It is important to note that the dramatic declines in cores and bridges from 1976 to 2018 , especially for the historical patches in the eastern and southwestern parts, which were smaller than those in the centre, caused the scattered distribution and difficulty of connection among historical patches in these regions. Small or moderately sized patches are not easily retained during the process of urban expansion compared to large patches (Wintle et al. 2018).

The most important cores were mainly concentrated in the central part of the study area, but they were severely threatened by the surrounding environments. Two large forest patches located in the centre were retained more integrally during 
urbanization because of their large area and steep topography. The core area of the two patches accounted for $31 \%$ of all the core areas in the study area; thus, they can provide the most ecological sources for the wild species in the city. However, they had high threat levels for several reasons. First, they were located in the most and earliest urbanized regions that were chronically disturbed by serious human pressures. In addition, the shapes of the patches were sinuous strips that had more edges. Complex shapes and more edges increase communication with surrounding environments and decrease the buffering capacity of habitat patches (Ewers and Didham 2006). This result indicates that the ecological functions of the patches in the central part may be alleviated due to the high threat levels, although they have a high probability of connectivity. This finding justified the necessity to integrate the evaluation of threat level, MSPA and the PC landscape metric to identify the critical area and recognize the potential risks of urban historical forests.

Bridges accounted for a smaller portion of spatial patterns in the study area, causing the cores to be more isolated. The area of bridges was only $7 \%$ of the total area of historical forests. A total of 198 cores in the study area had only 70 bridges connecting one another; thus, the ecological sources did not flow smoothly from most cores. In urban landscapes, corridors tend to be small in size compared to those in natural landscapes, as they are often not preserved. For example, the percentage of bridges in the urban forest landscape of Zhaoyuan city, China, was only $8 \%$ (Gao et al. 2019), while $35 \%$ of forests were estimated as bridges in the Cantabrian Mountains of Asturias and León regions, Spain (Velázquez et al. 2017). In addition, the most 
important bridges were found in the central region, which played a vital role in connecting the important cores and the connectivity of the whole landscape, but similarly, they were seriously threatened by their urban surroundings. In contrast, there were many corridor-lack areas in the southwestern, north-western and eastern regions. The historical forest fragments in these regions need to be improved by the addition of corridors.

Implications for the management of urban historical forests

Our finding that urbanization caused significant impacts on historical forests in Guiyang, China, can provide useful information for managing these historical forests, especially in the following aspects: 1) preventing the further massive loss of historical forestlands; 2) increasing the buffer area to protect the core areas; and 3) optimizing the corridor networks of urban forests.

Urban expansion has had significant impacts on historical forests. In the study area, $41 \%$ of historical forests were lost from 1976 to 2018 , and $75 \%$ of historical forest patches in 2018 were smaller than 10 ha. The size of 10 ha is regarded as a critical threshold size for maintaining the stability of urban forest patches (Ramalho et al. 2014), and small habitat patches are more likely to be lost in urban regions than large habitat patches. Therefore, conservation agencies should develop new ways to strictly control urban expansion into historical forestlands, such as establishing ecological red lines for protecting urban historical forests (Zhang and Ouyang 2014), especially small forests. To meet residents' demands for outdoor recreation, some large historical forest patches can be reformed to mountain parks. Trail networks 
should be carefully planned in these patches to avoid disturbing the areas that have high conservation value (Ballantyne and Pickering 2015). However, small patches are often more vulnerable and susceptible to human disturbance (Maiorano et al. 2008); thus, it is suggested they be enclosed by protective barriers to allow fewer residents in the forests.

Core areas of forests can provide important habitats and resources to interior wildlife (Pirnat and Hladnik 2016). However, core areas accounted for only $26 \%$ of the urban historical forest in the study area, and the most important cores were seriously threatened by their surroundings. The loss of historical forests is irreversible, but intentionally planted forests can also provide many ecosystem services and facilitate the remaining historical forests (Fernández et al. 2018). Planting tree belts surrounding historical patches as buffer areas is recommended to protect these forests. On the one hand, this measure can increase the size of integrated forest patches and enhance the buffer capability of historical forests. On the other hand, intentionally planting tree belts may adjust the shape complexity of the integrated patches and reduce the proportion of historical forests that is classified as edge area, which can increase the core areas and alleviate the threat levels of historical forests at the same time.

Corridors can make connections in the landscape, link isolated habitat patches, and facilitate ecological flows (Liang et al. 2018). Bridges connecting cores estimated in the study area were grossly insufficient. Creating ecological networks by planting forest corridors connecting core areas, especially for the small and isolated cores 
located in the eastern and southwestern regions, is also suggested to enhance the connectivity of the whole historical forest ecosystem. Single vegetation types of plantations should be avoided because of their poor resistance and weak ecological status (Hong et al. 2016). For the remaining bridges of historical forests, most of them are narrow, sensitive and easily damaged; thus, they require strict and special protection by human intervention.

\section{Conclusions}

Knowledge about the impacts of urban land use/cover change during urbanization on historical forests is needed to improve their management and conservation. In this study, we evaluated the area loss and levels of threats of historical forests and identified the critical areas for historical forests in Guiyang. Our results showed that urban expansion caused significant loss and an increase in threat levels for historical forests. The degradation risks of many of the most important cores and bridges for the connectivity of historical forest ecosystems were high due to the high urban intensity of the surrounding areas. Based on our results, we recommended active and efficient measures, such as preventing urban expansion into the remaining forestlands and planting tree belts to increase the buffer areas and forest corridors, which can enhance the connectivity of historical forests. We call for integrating the remaining historical forests into urban planning and nature conservation schemes. While Guiyang was regarded as a case study, the findings from our study will be useful for managing and conserving historical forests in other rapidly urbanizing cities. Future studies can further explore conservation priority areas combined with 
species distribution data built upon this study.

Authors'contributions

JY designed the study and drafted the manuscript, FW analysed the data. All authors commented preliminary versions of the manuscript and contributed to improve the final version. The author(s) read and approved the final manuscript.

Funding

This research was funded by the Guizhou Science and Technology Department under Grant (QKHLHZ[2016]7447) and The first-class discipline construction project of Guizhou Province under Grant (GNYL[2017]007).

Accessibility of data and materials

The data of land use/cover for built-up area of Guiyang, China and spatial locations of urban historical forest patches are available via the Mendeley Data Repository.

http://dx.doi.org/10.17632/mdjckk34r8.1

\section{Declarations}

Ethics approval and consent to participate

Not applicable.

Consent for publication

Not applicable.

Competing interests

The authors declare that they have no competing interests. 
References

Alberti M (2010) Maintaining ecological integrity and sustaining ecosystem function in urban areas. Curr Opin Sust 2:178-184.

http://doi.org/10.1016/j.cosust.2010.07.002

An Y, Liu S, Sun Y, Shi F, Beazley R (2020) Construction and optimization of an ecological network based on morphological spatial pattern analysis and circuit theory. Landscape Ecol 5. http://doi.org/10.1007/s10980-020-01027-3

Bagnall R (1979) A study of human impact on an urban forest remnant: Redwood Bush, Tawa, near Wellington, New Zealand. New Zeal J Bot 17:117-126. http://doi.org/10.1080/0028825X.1979.10426884

Ballantyne M, Pickering CM (2015) Differences in the impacts of formal and informal recreational trails on urban forest loss and tree structure. J Environ Manage 159:94-105. http://doi.org/10.1016/j.jenvman.2015.05.007

Caryl FM, Thomson K, Ree R (2013) Permeability of the urban matrix to arboreal gliding mammals: Sugar gliders in Melbourne, Australia. Austral Ecol 38:609616. http://doi.org/10.1111/aec.12006

Derkzen ML, Teeffelen AJ, Verburg PH (2015) REVIEW: quantifying urban ecosystem services based on high - resolution data of urban green space: an assessment for Rotterdam, the Netherlands. J Appl Ecol 52:1020 - 1032. http://doi.org/10.1111/1365-2664.12469

Ewers RM, Didham RK (2006) Confounding factors in the detection of species responses to habitat fragmentation. Biol Rev 81:117-142. 
http://doi.org/10.1017/S1464793105006949

Fahey RT, Casali M (2017) Distribution of forest ecosystems over two centuries in a highly urbanized landscape. Landscape Urban Plan 164:13-24. http://doi.org/10.1016/j.landurbplan.2017.03.008

Fernández IC, Wu J, Simonetti JA (2018) The urban matrix matters: Quantifying the effects of surrounding urban vegetation on natural habitat remnants in Santiago de Chile. Landscape Urban Plan. http://doi.org/10.1016/j.landurbplan.2018.08.027

Gao Y, Mu H, Zhang Y, Tian Y, Tang D, Li X (2019) Research on construction path optimization of urban-scale green network system based on MSPA analysis method: Taking Zhaoyuan City as an example. Acta Ecologica Sinica 39:75477556. http://doi.org/10.5846/stxb201905050907

Han Y, Kang W, Thorne J, Song Y (2019) Modeling the effects of landscape patterns of current forests on the habitat quality of historical remnants in a highly urbanized area. Urban for Urban Gree 41:354-363. http://doi.org/10.1016/j.ufug.2019.04.015

Hansen AJ, DeFries R (2007) Ecological mechanisms linking protected areas to surrounding lands. Ecol Appl 17:974-988. http://doi.org/10.1890/05-1098

Hong L et al. (2016) Study on plant diversity of mountain areas of yangmeikeng and chiao, shenzhen, china. American Journal of Plant Sciences 7:2527-2552. http://doi.org/10.4236/ajps.2016.717220

Hosonuma $\mathrm{N}$ et al. (2012) An assessment of deforestation and forest degradation 
drivers in developing countries. Environ Res Lett 7:044009. http://doi.org/10.1088/1748-9326/7/4/044009

Huang L, Chen H, Ren H, Wang J, Guo Q (2013) Effect of urbanization on the structure and functional traits of remnant subtropical evergreen broad-leaved forests in South China. Environ Monit Assess 185:5003-5018. http://doi.org/10.1007/s10661-012-2921-5

Isaksson C (2015) Urbanization, oxidative stress and inflammation: a question of evolving, acclimatizing or coping with urban environmental stress. Funct Ecol 29:913-923. http://doi.org/10.1111/1365-2435.12477

Ives CD, Hose GC, Nipperess DA, Taylor MP (2011) The influence of riparian corridor width on ant and plant assemblages in northern Sydney, Australia. Urban Ecosyst 14:1-16. http://doi.org/10.1007/s11252-010-0141-8

Kowarik I, von der Lippe M (2018) Plant population success across urban ecosystems: A framework to inform biodiversity conservation in cities. J Appl Ecol. http://doi.org/10.1111/1365-2664.13144

Kuhn I, Klotz S (2006) Urbanization and homogenization - Comparing the floras of urban and rural areas in Germany. Biol Conserv 127:292-300. http://doi.org/10.1016/j.biocon.2005.06.033

Laita A, Kotiaho JS, Mönkkönen M (2011) Graph-theoretic connectivity measures: what do they tell us about connectivity? Landscape Ecol 26:951-967. http://doi.org/10.1007/s10980-011-9620-4

Lees AC, Peres CA (2008) Conservation value of remnant riparian forest corridors of 
varying quality for Amazonian birds and mammals. Conserv Biol 22:439-449. http://doi.org/10.1111/j.1523-1739.2007.00870.x

Liang J et al. (2018) Integrating priority areas and ecological corridors into national network for conservation planning in China. Sci Total Environ 626:22-29. http://doi.org/10.1016/j.scitotenv.2018.01.086

Lopez BE, Urban D, White PS (2018) Nativity and seed dispersal mode influence species' responses to habitat connectivity and urban environments. Global Ecol Biogeogr. http://doi.org/10.1111/geb.12760

Maiorano L, Falcucci A, Boitani L (2008) Size-dependent resistance of protected areas to land-use change. P Roy Soc B-Biol Sci 275:1297-1304. http://doi.org/10.1098/rspb.2007.1756

Malkinson D, Kopel D, Wittenberg L (2018) From rural-urban gradients to patch matrix frameworks: Plant diversity patterns in urban landscapes. Landscape Urban Plan 169:260-268. http://doi.org/10.1016/j.landurbplan.2017.09.021

Niemelä J, Saarela S, Söderman T, Kopperoinen L, Yli-Pelkonen V, Väre S, Kotze DJ (2010) Using the ecosystem services approach for better planning and conservation of urban green spaces: a Finland case study. Biodivers Conserv 19:3225-3243. http://doi.org/10.1007/s10531-010-9888-8

Niu HY, Xing JJ, Zhang HM, Wang D, Wang XR (2018) Roads limit of seed dispersal and seedling recruitment of Quercus chenii in an urban hillside forest. Urban for Urban Gree 30:307-314. http://doi.org/10.1016/j.ufug.2018.01.023

Pirnat J, Hladnik D (2016) Connectivity as a tool in the prioritization and protection 
of sub-urban forest patches in landscape conservation planning. Landscape Urban Plan 153:129-139. http://doi.org/10.1016/j.landurbplan.2016.05.013

Ramalho CE, Hobbs RJ (2012) Time for a change: dynamic urban ecology. Trends in ecology \& evolution 27:179-188. http://doi.org/10.1016/j.tree.2011.10.008

Ramalho CE, Laliberte E, Poot P, Hobbs R (2018) Effects of fragmentation on the plant functional composition and diversity of remnant woodlands in a young and rapidly expanding city. J Veg Sci 29:285-296.

http://doi.org/10.1111/jvs.12615

Ramalho CE, Laliberte E, Poot P, Hobbs RJ (2014) Complex effects of fragmentation on remnant woodland plant communities of a rapidly urbanizing biodiversity hotspot. Ecology 95:2466-2478. http://doi.org/10.1890/13-1239.1

Ranta P, Viljanen V, Virtanen T (2013) Spatiotemporal dynamics of plant occurrence in an urban forest fragment. Plant Ecol 214:669-683. http://doi.org/10.1007/s11258-013-0198-6

Reider IJ, Donnelly MA, Watling JI (2018) The influence of matrix quality on species richness in remnant forest. Landscape Ecol:1-11. http://doi.org/10.1007/s10980-018-0664-6

Salghuna N, Prasad PRC, Kumari JA (2018) Assessing the impact of land use and land cover changes on the remnant patches of Kondapalli reserve forest of the Eastern Ghats, Andhra Pradesh, India. The Egyptian Journal of Remote Sensing and Space Science. http://doi.org/10.1016/j.ejrs.2018.01.005

Saura S, Torné J (2009) Conefor sensinode 2.2: a software package for quantifying the 
importance of habitat patches for landscape connectivity. Environmental Modelling \& Software 22:135-139.

http://doi.org/10.1016/j.envsoft.2008.05.005

Saura S, Vogt P, Velazquez J, Hernando A, Tejera R (2011) Key structural forest connectors can be identified by combining landscape spatial pattern and network analyses. Forest Ecol Manag 262:150-160. http://doi.org/10.1016/j.foreco.2011.03.017

Scheiner SM, Willig MR (2005) Developing unified theories in ecology as exemplified with diversity gradients. The American Naturalist 166:458-469. http://doi.org/10.1086/444402

InVEST +VERSION+ User's Guide (2016) The Natural Capital Project, Stanford University, University of Minnesota, The Nature Conservancy, and World Wildlife Fund. http://data.naturalcapitalproject.org/nightly-build/invest-usersguide/html/\#.

Smale M, Gardner R (1999) Survival of Mount Eden Bush, an urban forest remnant in Auckland, New Zealand. Pacific Conservation Biology 5:83-93. http://doi.org/10.1071/PC990083

Soga M, Kanno N, Yamaura Y, Koike S (2013) Patch size determines the strength of edge effects on carabid beetle assemblages in urban remnant forests. J Insect Conserv 17:421-428. http://doi.org/10.1007/s10841-012-9524-X

Soille P, Vogt P (2009) Morphological segmentation of binary patterns. Pattern Recognition Letters 30:456-459. http://doi.org/10.1016/j.patrec.2008.10.015 
Stamps JA, Buechner M, Krishnan VV (1987) The Effects of Edge Permeability and Habitat Geometry on Emigration from Patches of Habitat. Am Nat 129:533552. http://doi.org/10.1086/284656

Stiles A, Scheiner SM (2010) A multi-scale analysis of fragmentation effects on remnant plant species richness in Phoenix, Arizona. J Biogeogr 37:1721-1729. http://doi.org/10.1111/j.1365-2699.2010.02333.x

Terrado M, Sabater S, Chaplin-Kramer B, Mandle L, Ziv G, Acuna V (2016) Model development for the assessment of terrestrial and aquatic habitat quality in conservation planning. Sci Total Environ 540:63-70. http://doi.org/10.1016/j.scitotenv.2015.03.064

The Chinese State Council (2012) Several Opinions of the State Council on Further Promoting Sound and Fast Economic and Social Development in Guizhou. Velázquez J, J. G, Hernando A, A. G-A (2017) Evaluating landscape connectivity in fragmented habitats: cantabrian capercaillie ( tetrao urogallus cantabricus ) in northern spain. Forest Ecol Manag 389:59-67. http://doi.org/10.1016/j.foreco.2016.12.006

Vogt P, Ferrari JR, Lookingbill TR, Gardner RH, Riitters KH, Ostapowicz K (2009) Mapping functional connectivity. Ecol Indic 9:64-71. http://doi.org/10.1016/j.ecolind.2008.01.011

Williams NM, Winfree R (2013) Local habitat characteristics but not landscape urbanization drive pollinator visitation and native plant pollination in forest remnants. Biol Conserv 160:10-18. 
http://doi.org/10.1016/j.biocon.2012.12.035

Wintle BA et al. (2018) Global synthesis of conservation studies reveals the importance of small habitat patches for biodiversity. Proceedings of the National Academy of Sciences:1-6. http://doi.org/10.1073/pnas.1813051115

Xu X, Pang Z, Yu X (2014) Spatial-temporal pattern analysis of land use/cover change: methods \& application. Science and Technology Literature Press, Beijing

Yamaura Y, Kawahara T, Iida S, Ozaki K (2008) Relative importance of the area and shape of patches to the diversity of multiple Taxa. Conserv Biol 22:15131522. http://doi.org/10.1111/j.1523-1739.2008.01024.x

Yang J, Yang J, Xing D, Luo X, Lu S, Huang C, Hahs AK (2020) Impacts of the remnant sizes, forest types, and landscape patterns of surrounding areas on woody plant diversity of urban remnant forest patches. Urban Ecosyst. http://doi.org/10.1007/s11252-020-01040-z

Yang YC et al. (2014) Structure and diversity of remnant natural evergreen broadleaved forests at three sites affected by urbanization in Chongqing metropolis, Southwest China. Landsc Ecol Eng 10:137-149. http://doi.org/10.1007/s11355-011-0160-5

Yao L, Wu C, Lu Z (2018) Co-evolution Relationship Between the Quality of Urbanization and the Health of Land Use System in Karst Regions. Resources and Environment in the Yangtze Basin 27:768-778. http://doi.org/0.11870/cjlyzyyhj201804008 
Zhang H, Ouyang Z (2014) Practice and Consideration for Ecological Redlining. Bulletin of Chinese Academy of Sciences:457-461+448. http://doi.org/10.3969/j.issn.1000-3045.2014.04.008

Zipperer WC (2002) Species composition and structure of regenerated and remnant forest patches within an urban landscape. Urban Ecosyst 6:271-290. http://doi.org/10.1023/B:UECO.0000004827.12561.d4 


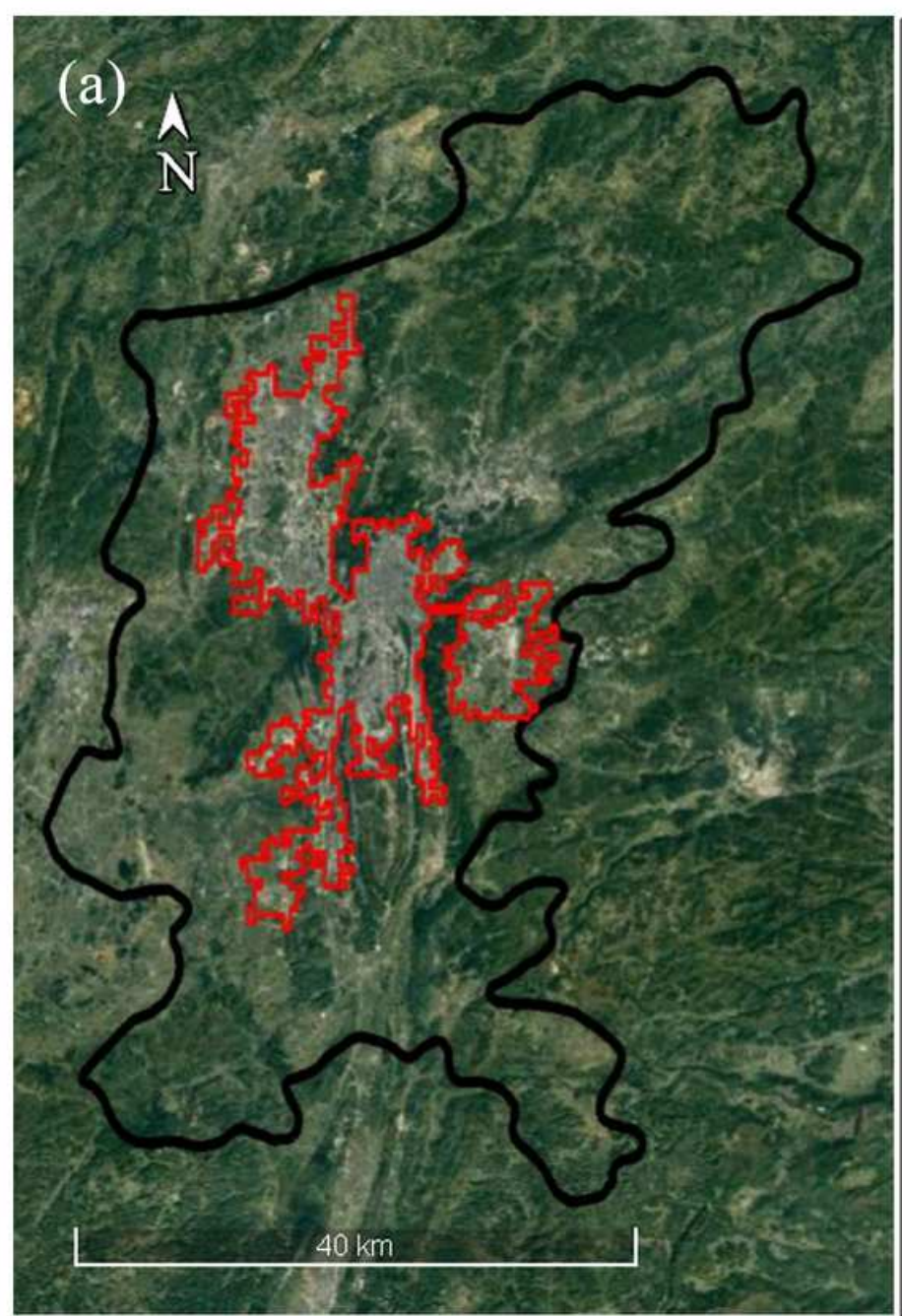

Administrative boundary Boundary of built-up area (b)

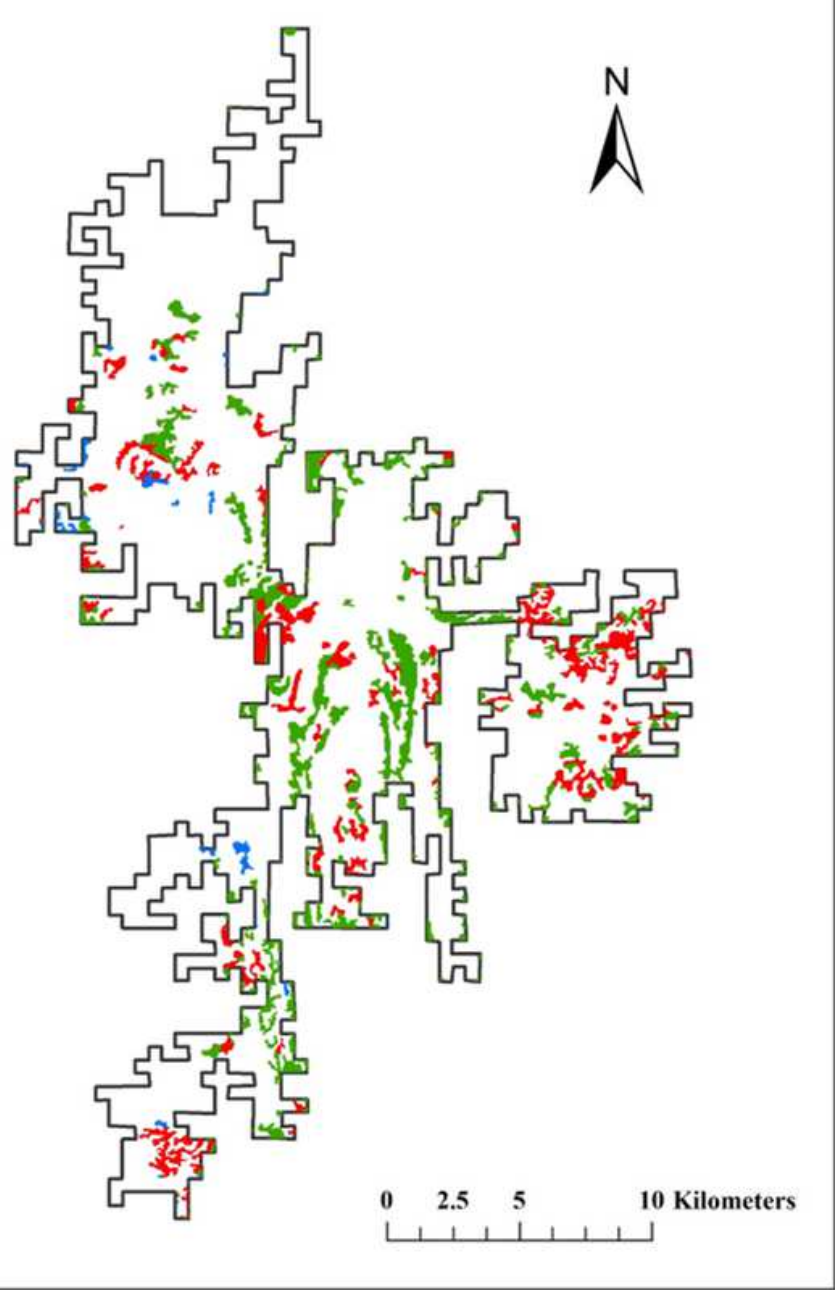

Historical forests in 2018

Forests in 1976 that have converted to other land use types in 2018 New forests planted after 1976 Boundary of built-up area

\section{Figure 1}

The locations of historical forests. (a) The administrative boundary (black line) and boundary of built-up area (red line); (b) locations of historical forests that were retained, those that were transformed, and newly planted forests. Note: The designations employed and the presentation of the material on this map do not imply the expression of any opinion whatsoever on the part of Research Square concerning the legal status of any country, territory, city or area or of its authorities, or concerning the delimitation of its frontiers or boundaries. This map has been provided by the authors. 


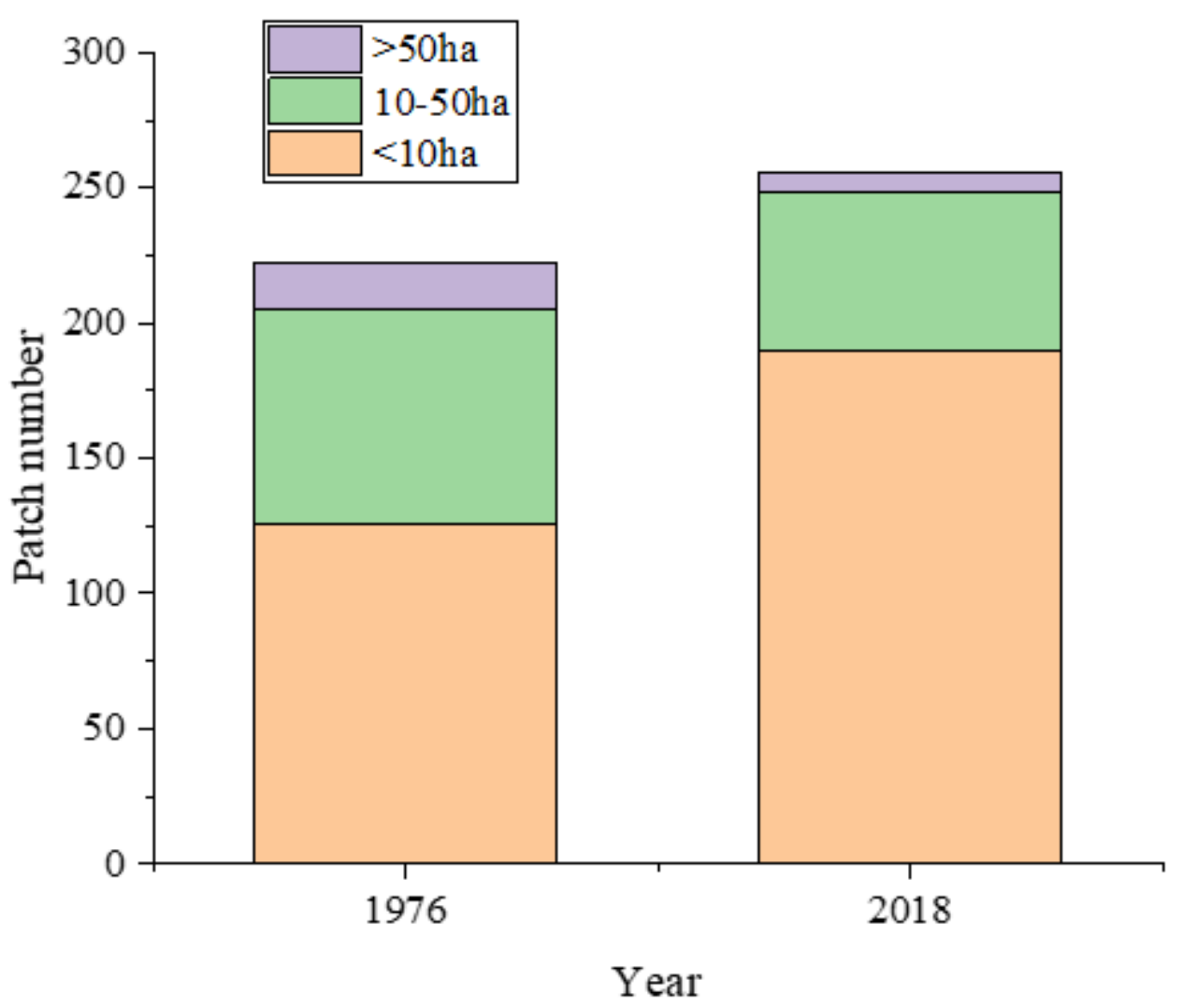

Figure 2

The number of historical forest patches. 


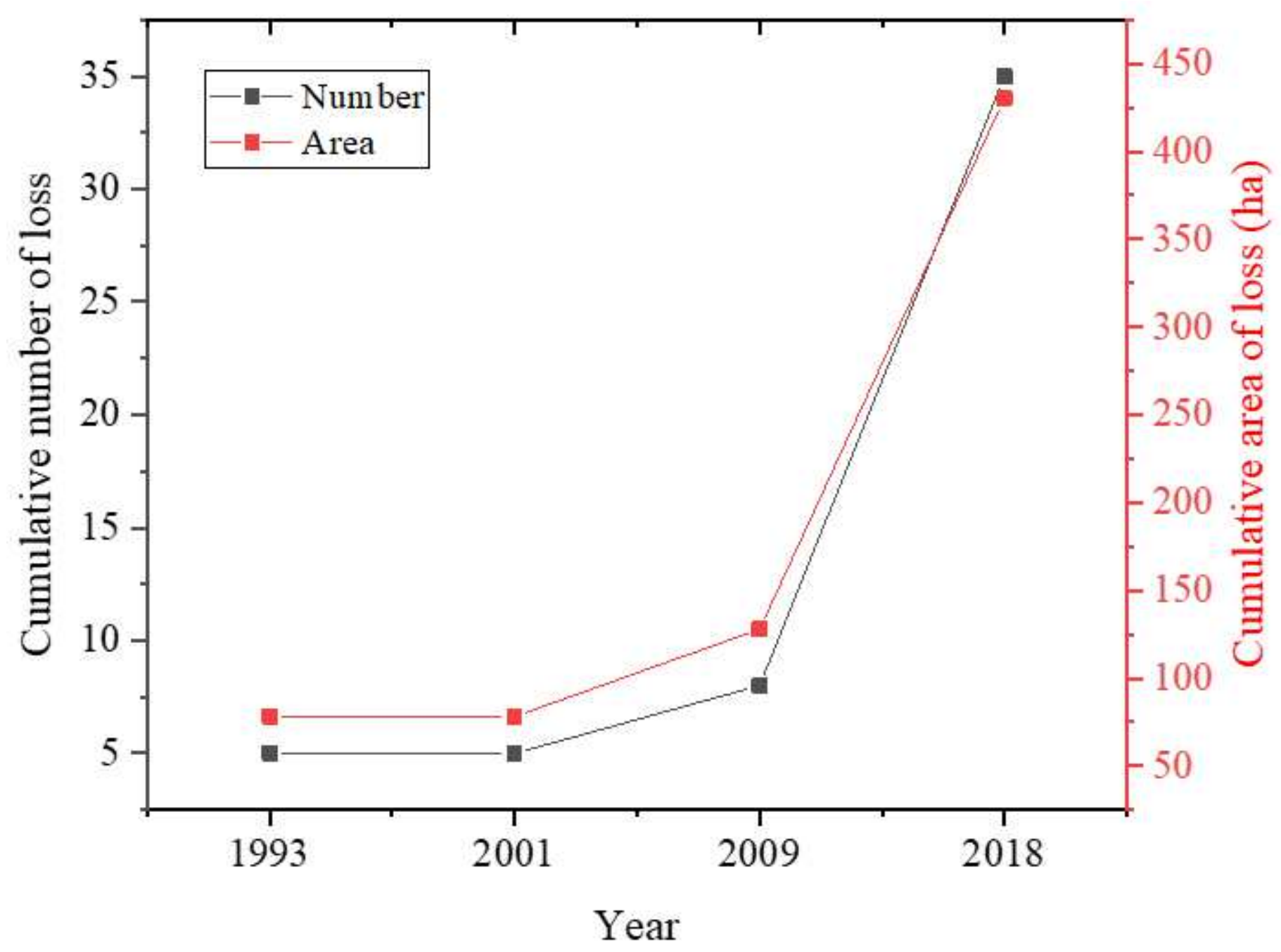

Figure 3

The cumulative numbers and areas of loss for forest patches that were fully transformed into other land use/cover types. 


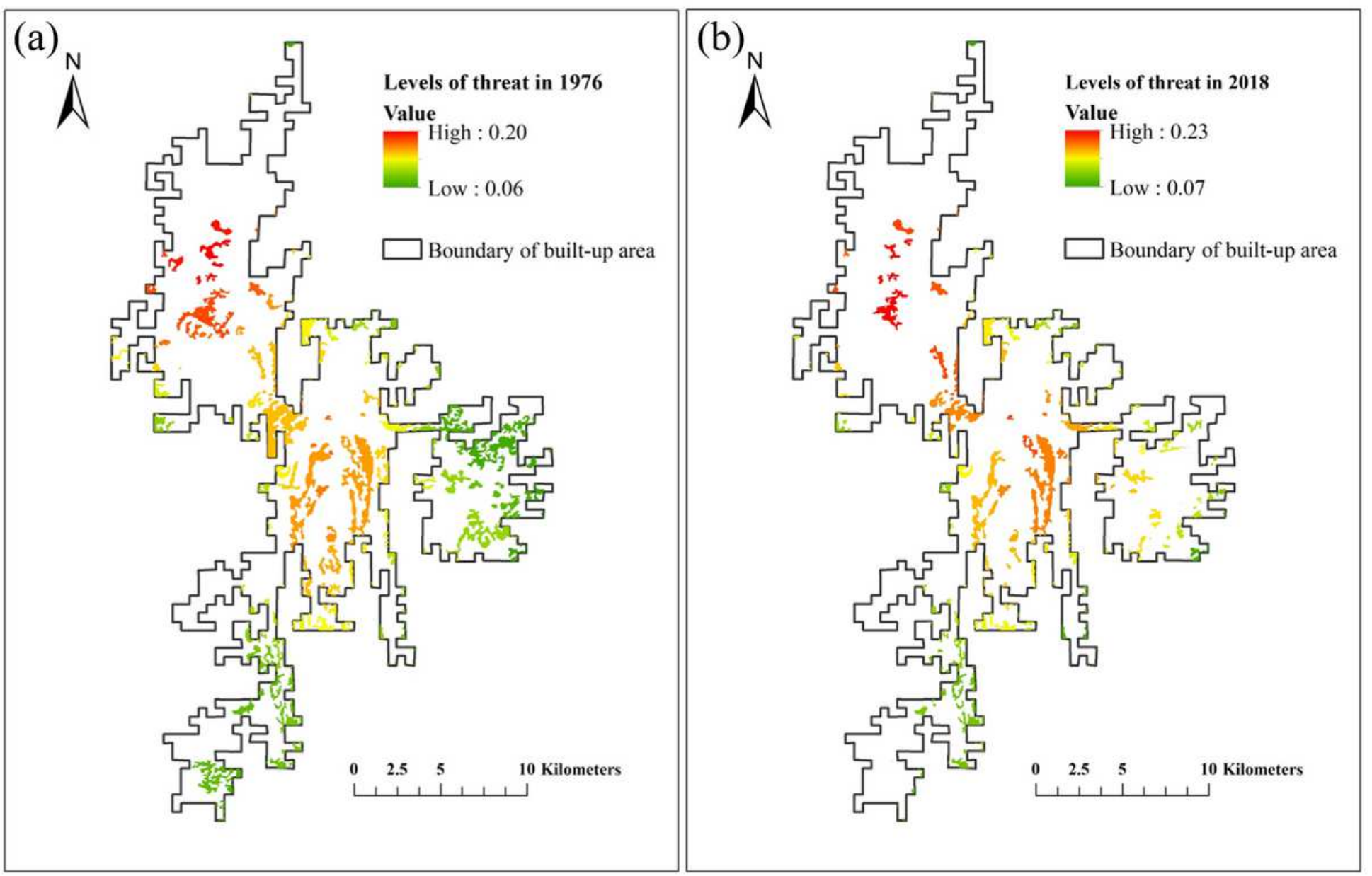

Figure 4

Levels of threat to historical forest patches in (a) 1976 and (b) 2018. Note: The designations employed and the presentation of the material on this map do not imply the expression of any opinion whatsoever on the part of Research Square concerning the legal status of any country, territory, city or area or of its authorities, or concerning the delimitation of its frontiers or boundaries. This map has been provided by the authors. 

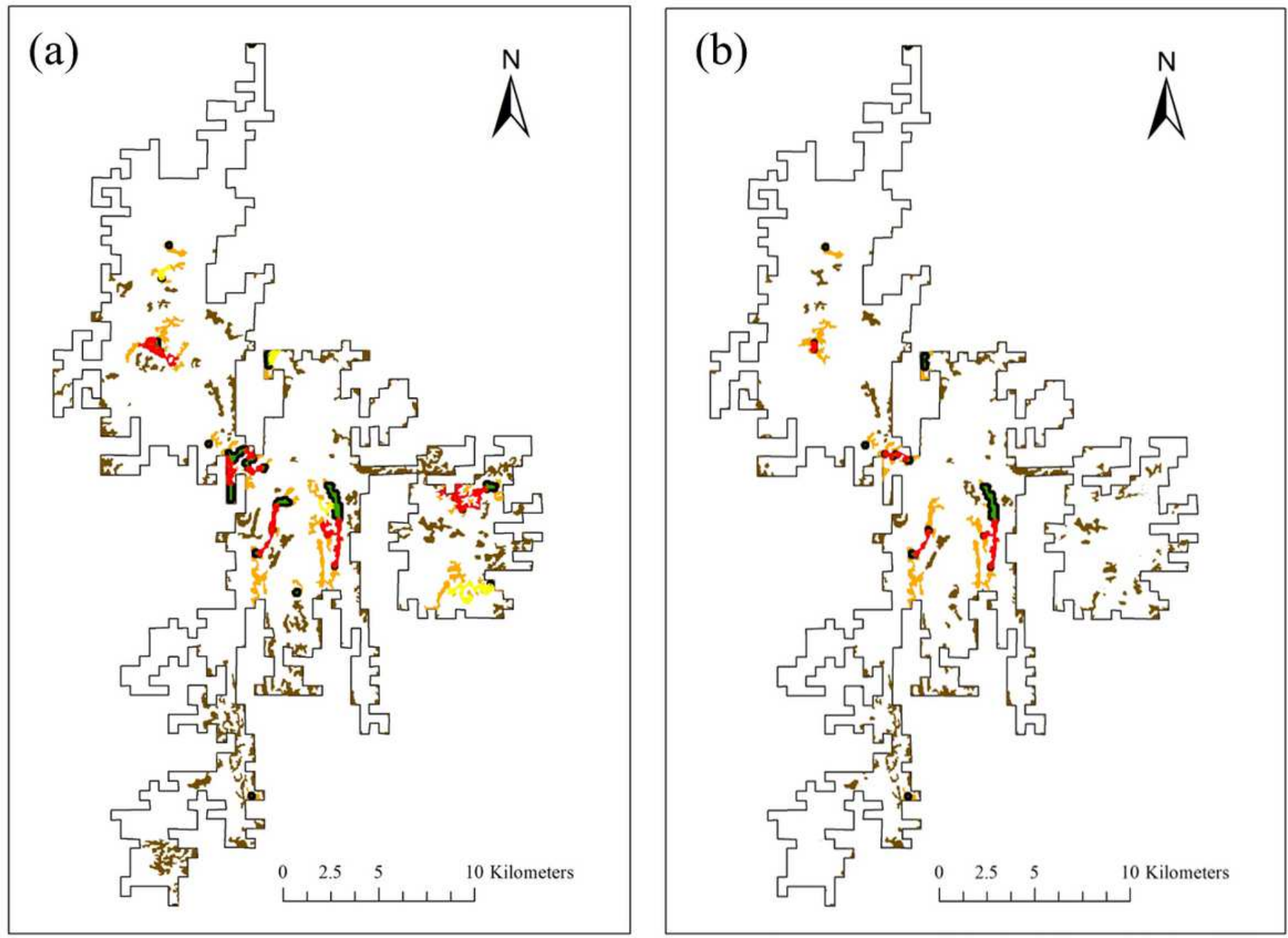

\section{Branch Edge $\square$ Islet}

\section{Figure 5}

Morphological spatial patterns of historical forests in (a) 1976 and (b) 2018. Note: The designations employed and the presentation of the material on this map do not imply the expression of any opinion whatsoever on the part of Research Square concerning the legal status of any country, territory, city or area or of its authorities, or concerning the delimitation of its frontiers or boundaries. This map has been provided by the authors. 


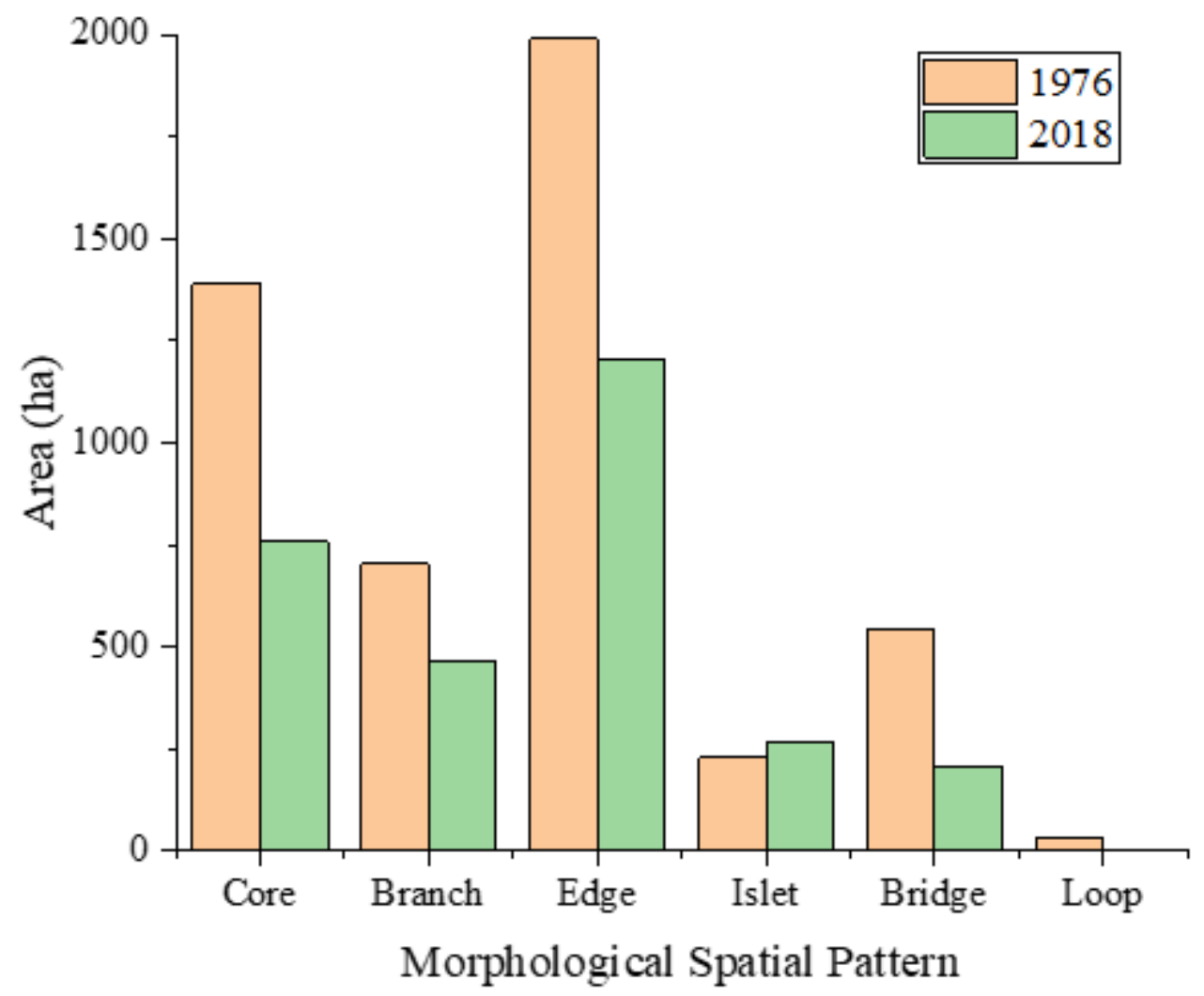

Figure 6

The areas of different morphological spatial pattern classes of historical forests in 1976 and 2018. 


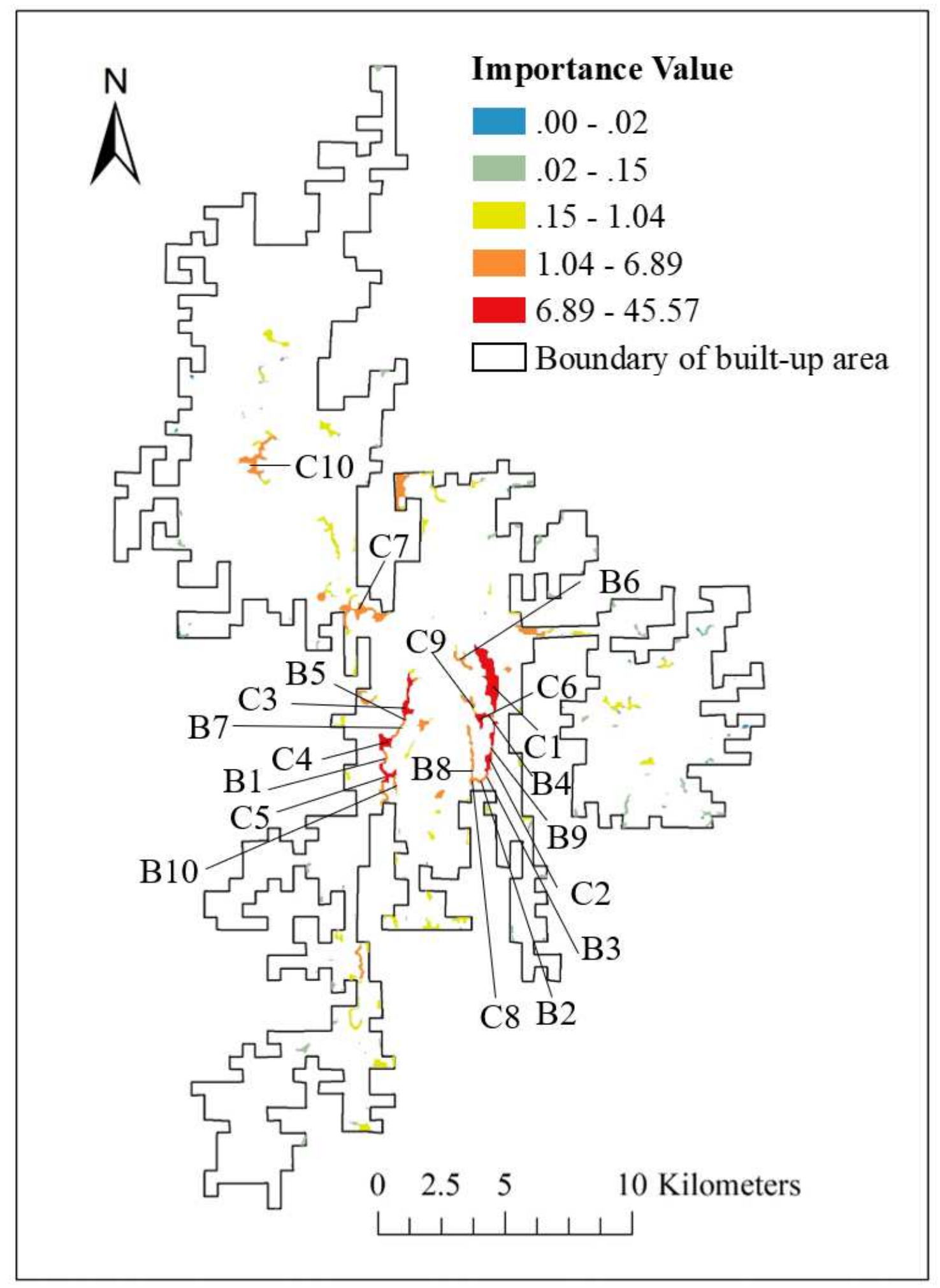

\section{Figure 7}

Probability of connectivity values for historical forest patches. Note: The designations employed and the presentation of the material on this map do not imply the expression of any opinion whatsoever on the part of Research Square concerning the legal status of any country, territory, city or area or of its authorities, or concerning the delimitation of its frontiers or boundaries. This map has been provided by the authors. 